\title{
ИГНОРИРОВАНИЕ КУЛЬТУРНО-ИСТОРИЧЕСКИХ И ПОЛИТИЧЕСКИХ ПОНЯТИЙ В ПЕРЕВОДЕ НЕМЕЦКОЙ ПОЭЗИИ НА РУССКИЙ ЯЗЫК
}

\section{IGNORING CULTURAL, HISTORICAL AND POLITICAL NOTIONS IN THE TRANSLATION OF GERMAN POETRY INTO RUSSIAN}

\section{F. Fidarova}

Summary: This article is dedicated to the analysis of ignoring cultural, historical and political German notions "nobel", "das neue Reich" and Völkisch during translation into the Russian language.

Being a major component of culture, poetry will help us understand that the notions "nobel", "das neue Reich" and "Völkisch" had been conditioned by that time and had determined a complex and fateful period in the culture and history of Germany. If one translates German poetry into Russian, but ignores these notions, they exclude a most important stratum of German history and culture. The stratum had orientated itself towards the cultural and national identity of Germans. These notions had actually prepared a twist in Germany's political culture, which is, as it is known, a part of the common culture.

As supporters of the patriotic movement, Goethe, Schiller and Stefan George determined the value of the aforementioned notions for the creation of a personality in the cultural and political space. Its basis had been set by the very history of Germany. The topicality of the theme consists in the fact that the analysis of the aforementioned notions reveals us the "slip" of the culture into the political sphere in Germany. We have established the types of poetically ignoring the said notions on the basis of Goethe, Schiller and George's texts.

Keywords: nobel, das neue Reich, Völkisch, morality, component of culture.

\author{
Фидарова Фатима Казантемировна \\ К.культурологии, доцент, Московский государственный \\ университет имени М.В. Ломоносова \\ fidarova@inbox.ru
}

Аннотация: Статья посвящена анализу игнорирования культурно-исторических и политических немецких понятий „благородный“, „Новый рейх“, „фёлькиш“ при переводе на русский язык.

Поэзия, как основной компонент культуры, поможет нам понять, что понятия „благородный“, „Новый рейх“, „фёлькиш“ обусловлены временем и определяют сложный и судьбоносный период в культуре и истории Германии. Игнорирование этих понятий при переводе немецкой поэзии на русский язык исключает важнейший пласт немецкой истории и культуры, который был ориентирован на культурную и национальную идентичность немцев. Эти понятия, по сути, подготовили поворот в политической культуре Германии, что является, как известно, частью общей культуры.

Гёте, Шиллер и Стефан Георге как сторонники патриотического движения определяют ценность указанных понятий для созидания личности в культурном и политическом пространстве, основание которого было заложено самой историей Германии. Актуальность данной темы заключается в том, что анализ указанных понятий раскрывает нам „соскальзывание“ культуры в сферу политического в Германии. Типы поэтического игнорирования указанных понятий мы устанавливаем с опорой на тексты Гёте, Шиллера, Георге.

Ключевые слова: благородный, Новый рейх, фёлькиш, нравственность, компонент культуры. емое нами явление культуры и политики.

Разумеется, слово, родное и иностранное поможет нам понять личность определенной эпохи и проникнуть в ее разнообразные роли.

Попробуем рассмотреть это на конкретном материале - в основном компоненте культуры, в поэзии. Стихотворение Шиллера «Начало нового века» (Der Antritt des neuen Jahrhunderts, 1801) является выражением культурно-исторической ситуации Германии, но также парадигмой ее игнорирования при переводе на русский язык:

Edler Freund! Wo öffnet sich dem Frieden,

Wo der Freiheit sich ein Zufluchtsort? 
Das Jahrhundert ist im Sturm geschieden,

Und das neue öffnet sich mit Mord [Schiller, B. 2, 1904: 155-156].

В переводе оригиналу этого стихотворения соответствуют строки:

Где приют для мира уготован?

Где найдет свободу человек?

Старый век грозою ознаменован,

И в крови родился новый век [Шиллер, т. 1, 2012: 282].

Часть первой строки - Благородный друг! выпадает из поля зрения переводчика.

В русском переводе, как было сказано, edler Freund, „благородный друг“ отсутствует. Однако именно он, edler Freund - друг, человек понимающий, разумный, наделенный добрыми помыслами, согласно Шиллеру, может осознать культурно-политическое положение своего отечества и сделать что-то необходимое, т. е. благородное и как патриот ускорить выход своего отечества из кризиса. На него, на edler Freund Шиллер возлагает свои надежды, именно благородный человек может стать опорой своего отечества.

Почему переводчик так легко опускает половину строки edler Freund, благородный друг? Главная причина заключается в следующем понимании этой проблемы.

В немецком языке необходимо четко различать понятие „благородный“ в старом значении принадлежности к "благородному роду“ (von edler Geburt) и его новое значение с XVIII века - духовные достоинства, душа и нравственность индивида. Однако духовные достоинства, душу и нравственность индивида, т. е. благородство в том значении, которое начинает утверждаться в бюргерской культуре XVIII века, можно осознать через метафору «благородство души и помыслов» [Grimm, 1984: 55].

Эволюцию значения слова „еdel“ всеобъемлюще исследовали Аделунг и Гримм. Однако, согласно Гримму, понятие «благородный с XVII-XVIII вв. становится выражением нравственного и эстетического потенциала внутреннего мира личности», т. е. оно неотделимо от внутренней культуры личности, от культурного кода, который заложен в человеке [Grimm, 1984: 55-62].

Культурологический анализ культурно-исторического контекста стихотворения Шиллера поможет нам осознать, декодировать символическое значение понятия „благородный“.

Культурно-историческую ситуацию, в условиях которой Шиллер писал свое стихотворение «Начало нового века» (Der Antritt des neuen Jahrhunderts, 1801) он затрагивает конкретно и характеризует очень выразительно: старый век грозою ознаменован,

и в крови родился новый век.

Исторический аспект этого периода для немецкой нации был судьбоносным. Как известно, в 1801 г. был заключен Люневильский мир, согласно которому французам был отдан левый берег Рейна. Однако уже до этого, 30 декабря 1797 года, Майнц был передан Франции. Таким образом, неприкосновенность империи была нарушена. Также многие немецкие князья в прирейнских областях сами открыто стремились к присоединению левого берега Рейна к Франции, поскольку «идея создания французской республики вызывала здесь огромную симпатию» [Scherr, 1856: 467].

Разумеется, Шиллер в своем стихотворении глубоко переживает за катастрофическое политическое положение старого Германского рейха, за свое отечество. Шиллер обращается к „благородному другу“ - edler Freund, который также понимает опасность потери политической независимости, что, как известно, неминуемо ведет к потере культурной идентичности.

Но почему именно к благородному другу, человеку обращается Шиллер? Для понимания специфики этой проблемы необходим анализ этого понятия в культурном пространстве Германии.

Утверждение понятия «благородство» (нем. edel, der Edelmut) в бюргерской культуре XVIII века в Германии происходит вместе с утверждением метафоры «благородства души и помыслов» [Grimm, 1984: 62].

В культурно-коммуникативном пространстве человека появляется новая категория понятия „благородный“ "как что-то нейтральное о том, для чего характерно нравственное величие» [Grimm, 1984: 62].

На этот новый культурный смысл понятия благородный у Гёте в драме «Торквато Тассо» Гримм и указывает: das Edle zu erkennen, ist Gewinst / der nimmer uns entrissen werden kann [Grimm, 1984: 62].

В русском переводе das Edle соответствует слово „прекрасное":

Прекрасное познала ты душой,

Твой выигрыш навеки неотъемлем [Гёте, Т. 5:111].

Однако перевод das Edle как „прекрасное“ исключает из нашего восприятия новый компонент этого понятия „нравственное величие“, о котором говорит Гримм.

В старом значении понятие „благородный“ в драме «Торквато Тассо» многократно употребляется и оно понятно как социальное поведение с определенным куль- 
турным кодом.

Социальное требование вести образ жизни, соответствующий своему сословию:

Коль хочешь знать о том, что подобает,

То спрашивай у благородных женщин [Гёте, Т. 5:238].

Игнорирование понятия „благородный“ edel мы находим также и в переводе стихотворения Гёте «Божественное» (Das Göttliche, 1785) на русский язык.

Главное требование к личности Гёте определяет в стихотворении «Божественное» и призывает искать его в человеческом сознании:

Edel sei der Mensch,

Hilfreich und gut!

Denn das allein

Unterscheidet ihn

Von allen Wesen

Die wir kennen [Gedichte, 2010: 185-187].

В переводе оригиналу этого стихотворения соответствуют строки:

Прав будь человек,

Милостив и добр:

Тем лишь одним

Отличаем он

От всех существ,

Нам известных [Гёте, Т. 1: 169-171].

Как видно, „еdel“, благородный в русском переводе заменен словом „прав“.

Мы думаем, однако, что для понимания смысла слов Гёте необходимо обратить внимание на последние строки этого стихотворения. Они также указывают, что „еdel“ употребляется в новом культурно-эстетическом значении, о котором говорит Гримм, а не в старом значении принадлежности к благородному роду:

Der edle Mensch

Sei hilfreich und gut!

Unermüdet schaff er

Das Nützliche, Rechte,

Sei uns ein Vorbild

Jener geahneten Wesen!

Гёте призывает быть нам примером не доброго человека, мало быть добрым человеком, а личности, которая в душе с этим новым компонентом культуры, а это личность разумная, осознающая культурно-исторические вызовы времени во благо своего отечества.

Гёте также ясно осознает значение edel для патриотического и культурного созидания личности без революционных потрясений, поскольку он сам был против всяких смут. Следует вспомнить в этом контексте его крылатое выражение из «Фауста» - мудрец не любит смут.

Слово edel у Гёте и Шиллера - это новая характеристика культурной роли понятия „благородный“, которую оно сыграло в развитии нового культурного и исторического поворота Германии.

Литературовед, филолог и теоретик культуры М. Бахтин указывает на сложность культурно-исторического познания чужого слова:

«Для художника-прозаика мир полон чужих слов, среди которых он ориентируется, к восприятию специфических особенностей которых у него должно быть чуткое ухо. Он должен ввести их в плоскость своего слова, притом так, чтобы эта плоскость не была бы разрушена» [Бахтин, 1994: 101].

Таким образом, у Гёте и Шиллера понятие „благородный“ выступает в аналогичной функции, когда оно относится ко второму смысловому пониманию - к исторической эпохе, в основе которой функционирует новое культурное наполнение и осмысление. Понятие „благородный“ стало для немцев культурным словом. «Культурное слово - преломленное сквозь авторитетный отстоявшийся medium слово» [Бахтин, 1994: 102].

Наряду с указанным понятием „благородный“ в немецком языке существует и другие понятия, русский перевод которых легко вводит в заблуждение, по сути, лишает нас осознания и понимания важнейшего периода в историческом, культурном и политическом пространстве Германии - причины прихода национал-социалистов к власти.

С особой ясностью мы видим это в стихотворении первого немецкого поэта-символиста Стефана Георге (Stefan George 1868-1933).

Заголовок, к которому прежде всего и относится наш комментарий, в русском переводе звучит так: «Новое царство» [История, 1968: 365].

\section{В оригинале ему соответствует:}

\section{Das neue Reich}

Der sprengt die Ketten, fegt auf Trümmerstätten

Die Ordnung, geißelt die Verlaufenen heim Ins ewige Recht wo Großes wiederum groß ist,

Herr wiederum Herr. Zucht wiederum Zucht; .er heftet Das wahre Sinnbild an das völkische Banner

Er führt durch Sturm und grausige Signale

Des Frührots seiner Treuen Schar zum Werk

Des wachen Tags und pflanzt das neue Reich [Linden. 1944: 339].

Георге написал свое стихотворение в 1928 году. Если 
оставаться на уровне образности, то перевод названия можно принять за выражение крайнего благополучия личности, не имеющей в своем недавнем прошлом проигранной Первой мировой войны и „позорного“ Версальского договора. Однако необходимо осознать, что личность, которая до начала Великой войны была „двигателем и носителем более высокой культуры“, утратила опору на свой любимый тысячелетний рейх [Gartenlaube, 1914:13].

Цель Георге - дать нам объясняющий образ своего видения Нового рейха и это для него как постижимое, поскольку он указывает нам, кто и как может осуществить эту всеми желанную идею.

Так у немцев исторически сложилось, что именно слово рейх, для политиков - термин, в сочетании Новый после проигранной войны станет для них новым политическим, культурным и экономическим ориентиром. Новый рейх означает, по сути, Третий рейх, поскольку рейх Бисмарка - это для немцев Второй рейх, но он перестал существовать. Веймарская республика приняла на себя все тяготы, которые обрушились на немцев и Германию после Версальского договора. Однако «Рейх во все времена был государством немецкого народа и для создания нового, обновленного рейх Бисмарка прекрасный образец» [Gartenlaube, 1931:3/1].

Также для понимания смысла названия стихотворения как рейх, а не царство следует принять во внимание тот факт, что немцы уже в 1923 году имели модель этого Нового рейха благодаря книге Меллера ван ден Брука «Третий рейх». Брук и ввел термин Третий рейх, который «окрылил национал-социалистов» [Gartenlaube, 1931:3/1].

В пятой строфе, к которой относится следующий комментарий, звучит в русском переводе так:

Он крепит верный символ на народное знамя [Цит. по Крейг, 1999: 73].

Das völkische Banner - фёлькиш знамя переведено как народное. В таком переводе мы утратили понимание мысли Георге о völkisch, однако без понимания истоков и смысла этого понятия мы теряем основное содержание текста, его культурно-политический посыл.

Обновление и возрождение Германии в качестве прежней великой державы должно было произойти путем объединения трех главных понятий: хозяин - фюрер с фёлькиш знаменами во главе „Нового рейха", т. е. Третьего рейха. Георге создает цепь из трех понятий, они синхронно взаимодействуют и образуют контекстуальную рамку для определения культурно-исторической и политической ситуации. Понятие фёлькиш в русском восприятии определяется как невыразимое и необъяснимое, поэтому его перевод как „народный“ представляет собой понятный образ. Такой перевод избавляет от внутренней противоречивости описываемого термина, но исключает его диахронию. Термин фёлькиш содержал в себе три главных требования: расовую теорию, название государства Третий рейх и возврат утраченных колоний. «Слово völkisch», благодаря «сочетанию таких разных значений, проделало для национал-социалистов огромную предварительную работу» [Broszat, 1958: 5168].

Эта тенденция соответствовала и националистическому движению фёлькиш. Эти три указанных термина являлись составляющим компонентом политических и националистических тенденций Германии после Первой мировой войны. Рейх и только „любимый рейх“ мог изменить для немцев катастрофическое положение отечества. Термин Новый или Третий рейх давал немцам надежду на возрождение своей политической культуры как составной части общей культуры. В этой связи мы не должны упускать из виду, «что важная роль в культуре всегда придается памяти» [Лисович, 2013:103, 109].

Рейх и его смысловое отягощенное содержание после нацизма в современном мире понятно. Однако культурно-историческая и политическая рамка этого термина гораздо шире, чем его простое восприятие через призму нацистского прошлого.

Его посредническая функция, состоящая в его способности „стоять“ между государством и немецким народом для изображения кризисной действительности и как великий и верный шанс для возрождения народа без военного столкновения с другими нациями, остается, как правило, в тени.

Понятия Новый рейх-Третий рейх, фюрер, фёлькиш стали основными терминами национал-социалистов. «Нацистский режим давно рухнул, но отголоски языка Третьего рейха все еще ощущаются в современном немецком языке. Они находят свое проявление в разных жанрах коммуникации, на всех уровнях языка, где наблюдается взаимодействие различных символов» [Едличко, 2015: 90-91].

Таким образом, наш анализ показывает, что мы в переводе сталкиваемся с чужим словом, которое представляет собой символическое пространство культуры и пространство истории и политики, они не разделяют наши понятия на два этапа, напротив, они синхронно взаимодействуют.

«Проблема ориентации речи на чужое слово имеет первостепенное социологическое значение. Слово по природе социально. Слово не вещь, а вечно подвижная, 
вечно изменчивая среда социального общения. Оно никогда не довлеет одному сознанию, одному голосу. Жизнь слова - в переходе из уст в уста, из одного контекста в другой контекст, от одного социального коллектива к другому, от одного поколения к другому поколению» [Бахтин, 1994: 101-102].

Слово völkisch, как мы видели, представляет проблему для переводчика, поскольку его перевод в словарях дается как „народный“ (в шовинистическом значении). Однако в немецком языке есть и другое слово со значением „народный“ - volkhaft. Выбор эквивалента зависит в данном случае от исторического знания переводчика. Эта историческая проблема, как было сказано выше, изначально возникла на культурно-политическом уровне. В аналогичной функции выступает и понятие „рейх“, поскольку в словарях оно представлено как государство, империя, рейх, иарство, сфера, область. Слово „рейх" несет в себе многочисленные коннотации, отсылающие нас и к нацистскому словоупотреблению, но поэты и писатели Германии пользовались им до прихода националсоциалистов в значении исторического названия своего государства.

На уровне текстов, создававшихся немецкими авторами после Первой мировой войны, смысловой потенциал понятий völkisch, „рейх“ получает значительное развитие, вектор которого был направлен в мирное будущее.

Вместе с тем из приведенных понятий явствует, что «сам язык ставит определенные границы возможностям правильного понимания чужого, которое от этого уклоняется. Языковые средства выражения во многих отношениях ограничены. Всегда существует недостаточность эквивалентности, которая не позволяет передать с абсолютной точностью какое-либо понятие или слово одним понятием и одним словом на другом языке. Примечательно, что такие речевые непреодолимости затрагивают как раз наиболее фундаментальные и, очевидно, универсально необходимые понятия» [Хёйзинга, 2010: 329].

Наряду с игнорированием переводчика при переводе, следует указать на наше собственное, „вынужденное игнорирование“, в основе которого коренится наше собственное незнание культурно-исторического и политического прошлого немцев.

Ярким примером в этом понимании вопроса являются политические стихотворения Фаллерслебена «Германия, Германия превыше всего» (Deutschland, Deutschland über alles, 1841) и Фридриха фон Штольберга «Мое отечество».

Если мы в политическом стихотворении Фаллерсле- бена «Германия, Германия превыше всего» (Deutschland, Deutschland über alles) будем опираться на наше историческое незнание или сознательное игнорирование смысла этих слов, то мы получим идеальный вариант для возбуждения крайнего национализма. С этой песней немцев так именно и происходило в политическом пространстве самой Германии и в других странах. Однако главная цель этих строк - создать единое централизованное государство с названием «Германия», Deutschland, которое отсутствовало в официальном названии страны после нашествия Наполеона.

Название страны Bund, Союз после победы над Наполеоном лишало немцев символа единого отечества, который являлся основой патриотического движения страны. Сила старого слова Германия, Deutschland должна была дать немцам чувство национальной и культурной идентичности

Еще один пример из немецкого культурного пространства, для которого необходимо историческое знание. Стихотворение Фридриха фон Штольберга «Мое отечество», написанное в 1774 году:

Да, немец я!

Лейтесь потоком радости слезы,

ведь немец я! [Цит. по Данн, 2003:49].

Как воспринимать эти строки: только чувство или пафос? Однако и эти строки для поэтов-патриотов являлись тогда призывом создать единую нацию „немцы“ вместо племенных названий баварцы, саксонцы, алеманы и т. д. [Данн, 2003: 35-45].

Как видно из приведенных источников, историческое незнание, в основе которого проблема политической культуры, легко вводит в заблуждение и таит в себе опасность, ослаблять культурно-коммуникативную функцию между народами. В основной компонент культуры, в поэзию вплетаются основные требования политической культуры немцев. «Политическая культура, культура общественно-политического общения, - это составная часть общей интегрированной культуры. Она сопрягается с другими составными частями этой культуры и отражает, как правило, некоторые основополагающие ценности той или культуры» [Юдина, 2001: 35].

Анализ содержания приведенных выше поэтических строк показывает, что для понимания смысла указанных понятий, которые ускользают от нашего определения и рассудочного постижения, мы должны обладать конкретным историческим знанием. Однако модель необъяснимости этих понятий изначально зародилась в культурно-политическом пространстве Германии. Понятийное осмысление концептов "благородный , „Новый рейх", „фёлькиш“"в поэзии говорит о том, что поэзия воздействует поверх всех понятий. Именно на эту особен- 
ность поэзии и указывает Гёте. «Поэзии, - заметил Гёте, - бесспорно присуще демоническое начало, и прежде всего поэзии бессознательной, на которую недостает ни разума, ни рассудка, отчего она так и завораживает нас» [Эккерман, 1999: 418].

Однако очевидно и то, что поэзия как основной компонент культуры освящает и сферу политического в Германии. Великий культуролог 20 века Хёйзинга считает подобную тенденцию как данность нашей эпохи. «С конца Первой мировой войны в мире, со всей очевидностью, протекает процесс, который я бы назвал соскальзыванием культуры в сферу политического, при том что культуру изначально и вполне сознательно оценивали по сравнению с политическим как наивысшее» [Хёйзинга, 2010: 325].

Однако это „соскальзывание“ культуры в сферу политического в Германии началось уже после победы над Наполеоном, когда немецкий народ в 1815 году вместо обещанной конституции и единого государства получил союзный договор и любимый немцами Рейх получил название Bund, Союз. Политические поэты Фаллерслебен и
Зимрок призывали вернуть стране название „Германия“, а Штольберг мечтал о единой нации „немцы“.

Патриотическая цель этих поэтов - через великое слово поэзии привести свою страну к политическому и культурному объединению.

Эта тенденция соответствовала политическому движению 18 века «немецкая культурная нация» [Данн, 2003: 48-49].

Таким образом, анализ наших понятий „благородный“, "Новый рейх", "фёлькиш" в немецкой поэзии показывает диахронию - как компонент немецкой культуры их культурно-символическое пространство дополняется и раскрывается пространством истории и политики. Они содержат в себе теоретическую проблему.

Теоретическая проблема, которую необходимо перевести на другой язык, должна быть ориентирована исторически. Историческая точка зрения необходима нам для понимания культуры и политики конкретного периода.

\section{ЛИТЕРАТУРА}

1. Бахтин М.М. Проблемы творчества поэтики Достоевского. Киев, 1994.

2. Гёте В. Собрание сочинений в 10 т. Т. 1,Т.5. М., 1977.

3. Данн 0. Нации и национализм в Германии 1770-1990. СПб, Наука, 2003.

4. Едличко А.И. Язык Третьего рейха и тенденции его проявления в современном протестном дискурсе. Вестн. Моск. ун-та. Сер. 19. Лингвистика и межкультурная коммуникация. 2015 №4.

5. История немецкой литературы. Т. 4. М., 1968.

6. Крейг Г. Немцы. М., Ладомир, 1999.

7. Лисович И.И. Трансформация культурной памяти и научное знание в Европе раннего Нового времени (научная статья)/ Знание. Понимание. Умение. 2013. №4.

8. Хёйзинга Й. Тени завтрашнего дня. Человек и культура. Затемненный мир. Спб., 2010.

9. Юдина Т.В. Теория общественно-политической речи. М., Московский университет, 2001.

10. Шиллер Ф. Собрание сочинений в 6 т. Т. 1. М., 2012.

11. Эккерман И.П. Разговоры о Гёте. Калининград, Янтарный сказ, 1999.

12. Broszat M. Die völkische Ideologie und der Nationalsozialismus. In: Deutsche Rundschau, 84, Heft 1. Januar 1958, S. 53-68.

13. Die schönsten deutschen Gedichte. Herausgegeben von Lukas Moritz. Köln, 2010.

14. Gartenlaube. Leipzig, 1914, 1931.

15. Grimm J, Grimm W. Deutsches Wörterbuch. B. 7. Leipzig, 1984.

16. Linden W. Deutsche Dichtung am Rhein. Ratingen, 1944.

17. Scherr J. Deutsche Kultur und Sitten Geschichte. Leipzig, 1858.

18. Schillers sämtliche Werke in 16 Bänden. B. 2. Stuttgart-Berlin, 1904.

(с) Фидарова Фатима Казантемировна (fidarova@inbox.ru). 